\title{
ARTICLE Context and topography determine the role of basolateral amygdala metabotropic glutamate receptor 5 in appetitive Pavlovian responding
}

\author{
Shaun Yon-Seng Khoo (iD) ${ }^{1}$, Mandy Rita LeCocq ${ }^{1}$, Ghislaine E. Deyab ${ }^{1}$ and Nadia Chaudhri ${ }^{1}$
}

\begin{abstract}
Preclinical data have shown that the excitatory metabotropic $\mathrm{Ga}_{\mathrm{q}}$-coupled glutamate receptor, mGluR5, has a role in substance abuse and relapse. However, little is known about the contribution of mGluR5 to the expression of conditioned responding elicited by appetitive Pavlovian cues. We investigated this question in rats that were trained to associate a discrete, auditory conditioned stimulus (CS) with a fructose-glucose solution (5.5\% fructose/4.5\% glucose; "sugar"). In subsequent tests for the expression of conditioned responding without sugar delivery, CS-elicited fluid port entries were elevated in a context associated with sugar, relative to an equally familiar, neutral context. Inhibiting mGluR5 via systemic injections of a negative allosteric modulator (MTEP; $5 \mathrm{mg} / \mathrm{kg}$ ) reduced CS port entries in both the sugar context and neutral context. Targeting MTEP microinjections ( $3 \mu \mathrm{g} / \mathrm{side}$; $0.3 \mu \mathrm{l} / \mathrm{min}$ ) to the nucleus accumbens (Acb) core had no effect on CS port entries at test, whereas the same manipulation in the basolateral amygdala (BLA) produced effects that were topographically dependent. Specifically, microinjecting MTEP in the posterior BLA had no effect on behavior, whereas inhibiting mGluR5 in the anterior BLA enhanced the contextual discrimination of CS port entries. These data are the first to show a role of mGluR5 in the context-dependent expression of appetitive Pavlovian conditioned responding, with a topographically defined arrangement of mGluR5 in the BLA being particularly important for context-based responding to a discrete, appetitive cue.
\end{abstract}

Neuropsychopharmacology (2019) 44:1524-1533; https://doi.org/10.1038/s41386-019-0335-6

\section{INTRODUCTION}

Altered glutamate homeostasis is hypothesized to play a major role in substance abuse [1], prompting considerable research on the role of the glutamatergic system in addiction $[2,3]$. The excitatory metabotropic $\mathrm{Ga}_{\mathrm{q}}$-coupled glutamate receptor, mGluR5 (nomenclatures: IUPHAR $=\mathrm{mGlu}_{5} ; \mathrm{HGNC}=\mathrm{GRM} 5$ ), has been studied in both human and non-human animals, and holds promise as a potential therapeutic target [4-12].

Preclinical animal models of relapse suggest that mGluR5 in the nucleus accumbens $(\mathrm{Acb})$ core and basolateral complex of the amygdala (BLA) mediates operant drug-seeking behavior that is reinforced by drug-predictive cues. For example, inhibiting mGluR5 through microinjection of the negative allosteric modulator 3-[(2-methyl-1,3-thiazol-4-yl)ethynyl]pyridine (MTEP) in the Acb core or BLA reduced cue-induced reinstatement of alcohol seeking [7], and MTEP microinjections into the Acb core reduced context-induced reinstatement (renewal) of cocaine seeking [13]. Less is known about the role of mGluR5 in conditioned responding that is acquired through Pavlovian conditioning and triggered by appetitive Pavlovian cues. This is an important question because drug-predictive cues can evoke craving and physiological responses that may precipitate relapse in people with substance use disorders [14].

Animal models of aversive Pavlovian conditioning suggest a role for mGluR5 in the acquisition and expression of this form of learning. For example, MTEP administration impaired the acquisition of aversive conditioning and acute administration prior to test reduced the expression of conditioned responding to an aversive conditioned stimulus $[15,16]$. Similarly, intra-BLA microinjections of MTEP during the acquisition of conditioned taste aversion rendered the conditioned taste aversion resistant to extinction [17]. In appetitive Pavlovian conditioning studies, inhibiting mGluR5 during acquisition prevented a cue from subsequently functioning as a conditioned reinforcer, suggesting that mGluR5 is needed for appetitive cues to acquire incentive properties [18]. These studies provide precedent for the hypothesis that glutamate transmission at mGluR5 plays a central role in behavior that is acquired through appetitive Pavlovian conditioning.

To test this hypothesis, we investigated the role of mGluR5 in the expression of conditioned responding to an appetitive Pavlovian conditioned stimulus (CS). Rats were trained to associate a discrete, auditory CS with the delivery of a $10 \%$ fructose-glucose solution ( $5.5 \%$ fructose $/ 4.5 \%$ glucose; "sugar"). We used this monosaccharide ratio because it is common in commercial foods and sweetened beverages and can alter dopamine function [19]. Moreover, palatable foods and sugar can induce neural adaptations and promote addiction-like behaviors [3, 20]. Because mGluR5 has been implicated in processing contextual information [12], we used a task that allowed us to examine the necessity of mGluR5 in responding to a CS that predicted sugar in a context

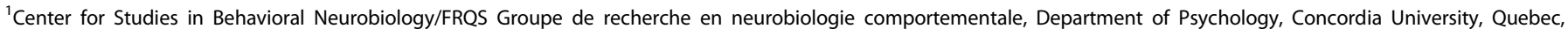
Montreal, Canada

Correspondence: Nadia Chaudhri (nadia.chaudhri@concordia.ca)

Received: 28 September 2018 Revised: 28 January 2019 Accepted: 3 February 2019

Published online: 8 February 2019 
Context and topography determine the role of basolateral amygdala... S. Y.-S. Khoo et al.

that was associated with sugar, as well as in a different, neutral context [21-23].

First, we examined the impact of the sugar-associated context on the expression of CS-elicited fluid port entries. Next, we examined the effect of systemically inhibiting mGluR5 (with MTEP) or NMDA glutamate receptors on CS port entries in both the sugar context and the neutral context. We chose MTEP because it is widely used to inhibit mGluR5 activity in studies of appetitive motivation [24]. Previous studies using MK-801 ((5R,10S)-(+)-5methyl-10,11-dihydro-5 $H$-dibenzo[ $a, d]$ cyclohepten-5,10-imine)

have implicated NMDA receptors in Pavlovian learning [25], and have shown interactions between NMDA receptors and mGluR5 [26-28]. We then investigated the Acb core and BLA as neuroanatomic loci for MTEP-mediated reductions in CS port entries. The BLA emerged as an important region, with an anteroposterior (AP) gradient within the BLA defining the impact of MTEP.

\section{METHODS}

\section{Animals}

We used 122 experimentally-naive, male, Long-Evans rats (Charles River, QC, Canada). Housing conditions are described in the supplementary materials and methods. Male rats were used to build on prior research on the role of the glutamate system in appetitive Pavlovian behavior [21]; however, future studies will extend this work to female rats. Rats had unrestricted access to food (Teklad, Envigo, QC, Canada) and water throughout the experiments. All procedures were approved by the Animal Research Ethics Committee at Concordia University and performed in accordance with guidelines from the Canadian Council on Animal Care.

\section{Surgery}

Using standard stereotaxic procedures [21], rats in separate microinjection experiments received bilateral, 26 ga cannulae (Plastics One, Roanoke, VA, USA) targeting the Acb core, the BLA, or a more anterior portion of the BLA. Coordinates in $\mathrm{mm}$ from bregma were: Acb core, $+1.5 \mathrm{AP}, \pm 3.23 \mathrm{ML}$ on a $10^{\circ}$ angle, and $-4.3 \mathrm{~mm} \mathrm{DV} ; \mathrm{BLA},-2.54 \mathrm{AP}$, $\pm 5 \mathrm{ML}$, and $-5.5 \mathrm{DV}$; anterior $\mathrm{BLA},-2.1 \mathrm{AP}, \pm 4.9 \mathrm{ML}$, and $-5.5 \mathrm{DV}$.

Drugs and solutions

MTEP hydrochloride (Cat\# A15174, CAS\#: 1186195-60-7, Lot\# L15174B001) and MK-801 (Cat\# A12761, CAS\#: 77086-22-7, Lot\# L12761B001) were obtained from Adooq Bioscience (Irvine, CA, U.S.A.). Drugs were dissolved in a vehicle solution of $5 \%$ DMSO/ $0.9 \%$ sterile saline. A $10 \%$ fructose-glucose solution (hitherto referred to as "sugar") was prepared by dissolving $55 \mathrm{~g} / \mathrm{L}$ fructose and $45 \mathrm{~g} / \mathrm{L}$ glucose in tap water (Cat\#: FRC180 and GLU501, CAS\#: 57-48-7 and 50-99-7, BioShop, ON, Canada).

\section{Apparatus}

Behavioral training was conducted using 12 identical conditioning chambers $(30.5 \times 31.8 \times 29.2 \mathrm{~cm}$, Cat\#: ENV-009A, Med Associates, St Albans, VT, USA) that are described in the supplementary materials and methods.

\section{General behavioral procedures}

Home-cage exposure to sugar. Rats were pre-exposed to sugar for $48 \mathrm{~h}$ in their home-cages. A pre-weighed fluid receptacle containing $90 \mathrm{~mL}$ of sugar was placed on the home-cage. This bottle was re-weighed $24 \mathrm{~h}$ later, refilled to $90 \mathrm{~mL}$, and then weighed again after $24 \mathrm{~h}$. Rats consumed all, or nearly all, of the sugar.

Pavlovian conditioning with context discrimination. Rats were habituated to transport and the conditioning chambers over three days (see supplementary materials and methods).

They were then assigned to one of two contexts for Pavlovian conditioning sessions (the sugar context), while the remaining
Table 1. Description of contexts used for Pavlovian conditioning with context discrimination

\begin{tabular}{|c|c|c|}
\hline Modality & Context 1 & Context 2 \\
\hline \multirow[t]{2}{*}{ Visual } & $\begin{array}{l}\text { Black cardboard-covered } \\
\text { sides }\end{array}$ & No covers (clear acrylic) \\
\hline & Brown paper in waste pan & White paper in waste pan \\
\hline Tactile & Acrylic glass floor & Wire grid floor \\
\hline Olfactory $^{a}$ & $10 \%$ lemon oil & $\begin{array}{l}10 \% \text { almond odor } \\
\text { (benzaldehyde) }\end{array}$ \\
\hline
\end{tabular}

${ }^{a}$ Sprayed onto a clear petri dish located in the waste pan beneath the chamber floor

context served as the familiar, neutral context (see Table 1 for description of contexts). Discrete stimuli were a $10 \mathrm{~s}$, continuous white noise or $10 \mathrm{~s}$ of a $5 \mathrm{~Hz}$ clicker. Rats were assigned one stimulus (the conditioned stimulus or CS) to be paired with sugar delivery in the sugar context and the other (the neutral stimulus or NS) to be presented without sugar in the neutral context. The purpose of the NS was to equate the acoustical salience of both contexts. Rats were counterbalanced across contexts, stimuli, and session order such that there were no differences in home-cage sugar consumption or bodyweight. Rats were then given one training session a day that alternated between each context until they had received 10 sessions of Pavlovian conditioning in the sugar context and 10 sessions of exposure to the NS in the neutral context.

During training sessions, rats received 10 stimulus presentations (either CS or NS as per the appropriate context) with intervals of 120,240 , or $360 \mathrm{~s}$ between trials (mean inter-trial interval (ITI) $=$ $240 \mathrm{~s}$ ), with each trial consisting of a $10 \mathrm{~s}$ Pre-CS/NS interval, $10 \mathrm{~s}$ CS/NS presentation, and $10 \mathrm{~s}$ post-CS/NS interval. In the sugar context, presentations of the CS co-terminated with $6 \mathrm{~s}$ of syringe pump operation to deliver $0.2 \mathrm{~mL}$ of fructose-glucose ('sugar') solution. In the neutral context, NS presentations also coterminated with $6 \mathrm{~s}$ of syringe pump operation, but no syringes were present and thus no sugar was delivered.

Testing. At $24 \mathrm{~h}$ after the last training session, the expression of conditioned responding elicited by the CS was tested in the absence of sugar. Tests occurred in the sugar context and the neutral context for each rat, with 1-2 sessions of retraining in each context between tests. At test, the CS was presented as during prior Pavlovian conditioning sessions and the syringe pump was activated for $6 \mathrm{~s}$, but no syringes were present and thus no sugar was delivered. The NS was never presented at test. Moreover, our preliminary data indicate that the NS does not elicit port entries when presented alone in either the sugar or neutral contexts [29].

Four separate experiments (described in detail in the supplementary materials and methods) were conducted using this behavioral procedure.

Histology

Standard histological procedures [21] were used to visualize placements of the microinjectors within targeted brain regions (see supplementary materials and methods).

Data analyses and availability of materials

Statistical analyses were performed using SPSS 24 (IBM, NY, USA), and included paired $t$-tests, repeated measures ANOVA, mixed-design ANOVA, Bonferroni-corrected post-hoc comparisons, and Pearson correlations. For repeated measures ANOVA, Greenhouse-Geisser sphericity corrections were used when $\varepsilon<0.75$. The non-parametric Friedman's Two-Way ANOVA was used when data violated assumptions of homogeneity of variance. 
The behavior we measured was entries into the fluid port during different intervals of the session. These intervals included $10 \mathrm{~s}$ before each CS/NS (Pre-CS/NS), the $10 \mathrm{~s}$ CS/NS, and the variable inter-trial interval (ITI). Conditioned responding is depicted as an elevation score, calculated by subtracting Pre-CS port entries from CS port entries [30,31].

Each experiment was run as a single replicate. The underlying raw data and Med-PC code are available on Figshare [32].

\section{RESULTS}

CS port entries were selectively elevated in the sugar context We previously reported a reliable and selective elevation in port entries elicited by a CS that predicted alcohol in an alcohol context, relative to a neutral context [21]. The impact of context on port entries elicited by a CS that predicted sugar is unknown. To examine this question, rats $(n=17)$ were trained and tested as described above (Fig. 1a). At test, CS port entries were elevated in the sugarassociated context, relative to the equally familiar, neutral context. Normalized CS port entries (Fig. 1b) were significantly higher at test in the sugar context than the neutral context $\left(t_{16}=4.268, p=0.001\right)$, and the latency to make a port entry after CS onset was significantly shorter in the sugar context than in the neutral context (Fig. 1c; $t_{16}$ $=-6.235, p<0.001)$. Context had no effect on port entries made during the ITI (Fig. $1 \mathrm{~d} ; t_{16}=0.349, p=0.699$ ), indicating a selective influence of context on CS port entries.

An analysis of within-session responding at test found that the number of port entries made during each CS trial decreased across trials (Fig. 1e; Trial, $F_{9,144}=9.876, p<0.001$ ), with more overall CS port entries in the sugar context (Context, $F_{1,16}=23.14, p<0.001$ ) but a comparable decrease across CS trials in both contexts (Context $\times$ Trial interaction, Greenhouse-Geisser corrected, $\varepsilon=$ $0.537 ; F_{4.836,77.378}=0.567, p=0.72$ ).

Systemic administration of MTEP, but not MK-801, reduced CS port entries in both contexts

In the same rats, we assessed the contribution of NMDA receptors and mGluR5 in the expression of CS port entries in both contexts. Prior to tests in either context, rats received an injection of vehicle, $0.1 \mathrm{mg} / \mathrm{kg}$ MK-801, or $5 \mathrm{mg} / \mathrm{kg}$ MTEP according to a withinsubjects, Latin Square design. These doses have been shown previously to affect dopamine release in the prefrontal cortex [27] and reinstatement of methamphetamine and cocaine seeking [33, 34]. At test, normalized CS port entries were significantly higher in the sugar context than in the neutral context (Fig. 2a; Context, $\left.F_{1,16}=45.122, p<0.001\right)$. ANOVA indicated a significant main effect of Treatment $\left(F_{2,32}=23.166, p<0.001\right)$ that did not differ across contexts (Context $\times$ Treatment, $F_{2,32}=2.157, p=0.132$ ). Bonferroni-corrected post-hoc comparisons revealed a significant reduction in CS port entries following MTEP, relative to vehicle or MK-801 ( $p<0.001$ for both comparisons), suggesting that inhibiting mGluR5 reduced CS port entries regardless of the context in which the CS was presented.

Latency to the first CS port entry followed the same pattern. At test, CS port entries were initiated more rapidly in the sugar context (Fig. $2 \mathrm{~b}$; Context, $F_{1,16}=37.477, p<0.001$ ) and there was a significant main effect of Treatment (Greenhouse-Geisser corrected, $\left.\varepsilon=0.69, F_{1.381,22.09}=32.484, p<0.001\right)$. The effect of MTEP did not differ between contexts (Context $\times$ Treatment, $F_{2,32}=$ 1.283, $p=0.291$ ). Bonferroni-corrected post-hoc comparisons indicated a significant increase in latency following MTEP, relative to vehicle $(p=0.001)$ or MK-801 $(p<0.001)$.

There was no impact of Context $\left(F_{1,16}=1.056, p=0.319\right)$ or Treatment $\left(F_{2,32}=1.494, p=0.24\right)$ on ITI port entries (Fig. $2 \mathrm{c}$ ), and no Context $\times$ Treatment interaction (Greenhouse-Geisser corrected, $\left.\varepsilon=0.719, F_{1,439,23.019}=0.31, p=0.664\right)$.

We examined the number of port entries in each CS trial to determine if inhibiting NMDA receptors or mGluR5 influenced the pattern of responding that emerged at test (Fig. 2d, e). The number of port entries was higher at test in the sugar context relative to the neutral context (Context, $F_{1,16}=39.086, p<0.001$ ), and decreased as a function of CS trial (Trials, $F_{9,144}=4.465, p<$ 0.001 ), comparably in both contexts (Context $\times$ Trial, $F_{9,144}=1.495$, $p=0.155)$. This analysis recapitulated a significant main effect of Treatment $\left(F_{2,32}=23.642, p<0.001\right)$, with no Context $\times$ Treatment interaction $\left(F_{2,32}=2.149, p=0.133\right)$. Interestingly, however, the effect of MTEP differed as a function CS trial (Treatment $\times$ Trial, $\left.F_{18,288}=3.038, p<0.001\right)$ in the sugar and neutral contexts (Context $\times$ Treatment $\times$ Trial, $F_{18,288}=1.862, p=0.019$ ). In the sugar context (Fig. 2d), MTEP reduced CS port entries in trials 2, 3 , and 4 compared to vehicle and MK- $801(p \leq 0.006)$, and in trial 5 compared to MK-801 $(p=0.02)$. In the neutral context (Fig. 2e), MTEP reduced CS port entries in trials 1,2 , and $3(p \leq 0.042)$ compared to vehicle and MK-801, and in trial 5 compared to MK-801 $(p=0.049)$.

Although MK-801 had no effect on responding in this experiment, we found in a separate experiment that prior repeated exposure to $0.1 \mathrm{mg} / \mathrm{kg}$ MK-801 induced a selective sensitization of CS port entries, indicating that it was a behaviorally effective dose (Fig. S1).

Additional experiments in separate rats indicated that systemic injection of MTEP $(5 \mathrm{mg} / \mathrm{kg}$ ) had no impact on locomotor behavior in an open field test (Fig. S2) or on the consumption of fructoseglucose solution in the home-cage (Fig. S3)

Thus, blocking NMDA glutamate receptors had no impact on the expression of CS port entries. However, inhibiting mGluR5 selectively reduced responding to the appetitive CS without causing a non-specific reduction in locomotor behavior or a change in the hedonic properties of sugar. Moreover, MTEP reduced CS port entries immediately in the neutral context, but this effect only emerged in the second CS trial in the sugar context.

MTEP in the nucleus accumbens core had no effect on CS port entries

In separate rats $(n=21)$, we examined the effect of MTEP microinjection into the Acb core on CS port entries in the sugar and neutral contexts (Fig. 3a), at a dose previously shown to reduce cue-induced reinstatement of alcohol seeking [7]. At test, CS port entries were significantly elevated in the sugar context relative to the neutral context (Context, $F_{1,13}=31.338, p<0.001$ ). However, MTEP in the Acb core did not affect CS port entries (Treatment, $F_{1,13}=0.013, p=0.909$ ) in either context (Context $\times$ treatment, $\left.F_{1,13}=1.361, p=0.264\right)$.

MTEP in the Acb core had no effect on latency to the first CS port entry (Fig. 3b). While responses occurred more rapidly in the sugar context than the neutral context (Context, $F_{1,13}=$ 112.742, $p<0.001$ ), MTEP did not affect latency (Treatment, $F_{1,13}=0.067, p=0.799$ ) in either context (Context $\times$ treatment, $\left.F_{1,13}=0.026, p=0.874\right)$. There was also no effect of MTEP in the Acb core on CS port entries on a per trial basis (Fig. S4a).

An analysis of ITI port entries (Fig. 3c) revealed no effect of context $\left(F_{1,13}=0.081, p=0.78\right)$ and no impact of intra-Acb core MTEP on ITI port entries (Treatment, $F_{1,13}=1.042, p=0.326$ ) in either context (Context $\times$ Treatment, $F_{1,13}=1.078, p=0.318$ ).

The placements of microinjector cannulae for all rats are depicted in Fig. 3d (see also Fig. S5a). Two rats were excluded from the analyses due to lost head mounts and 5 rats were excluded following histology (final $n=14$ ).

Thus, mGluR5 in the Acb core did not appear necessary for the expression of CS port entries.

MTEP in the basolateral amygdala-support for more anterior basolateral amygdala targeting

We then examined the effect of MTEP microinjection into the BLA (total $n=20$ ) on CS port entries in the sugar and neutral contexts 


\section{CS port entries were elevated and faster to occur in a sugar context relative to an equally familiar but neutral context}
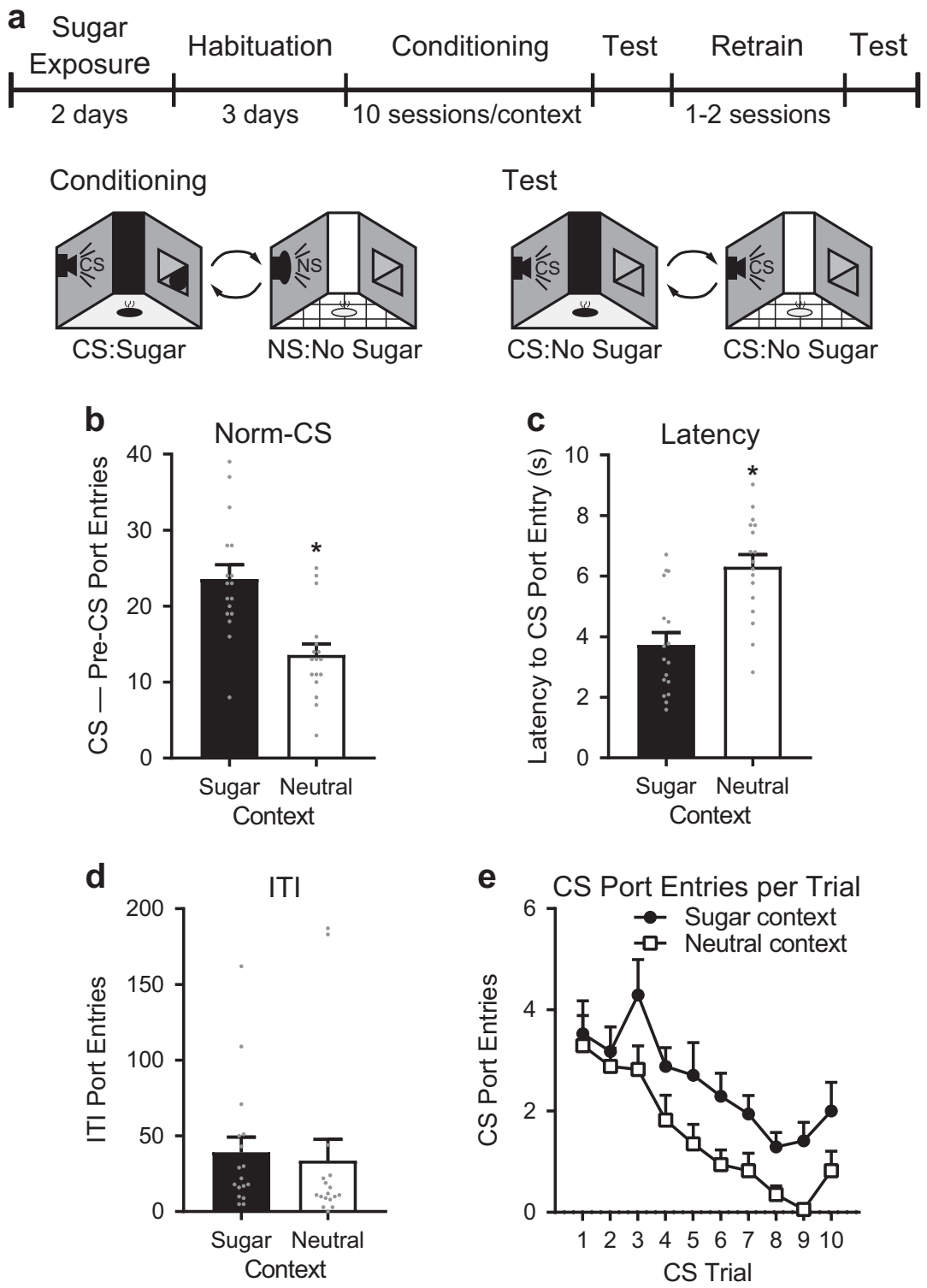

Fig. 1 CS port entries were elevated and faster to occur in a context associated with sugar compared to an equally familiar, neutral context. a Rats $(n=17)$ were exposed to sugar in the home-cage and then habituated to transport and contexts over 3 days. Rats were then trained to associate one auditory conditioned stimulus (CS) with sugar in one context (sugar context) and given equal exposure to a distinct, neutral context where a different, neutral auditory stimulus (NS) was presented without sugar. Contextual configurations were counterbalanced between the sugar and neutral contexts (see description in Table 1). At test, the CS was presented without sugar in both contexts, with retraining between tests. b At test, normalized CS port entries (CS-Pre-CS port entries) were elevated in the sugar context compared to the neutral context. $\mathbf{c}$ Latency to the first CS port entry was shorter in the sugar context than the neutral context. $\mathbf{d}$ There was no effect of context on the number of port entries made during the inter-trial intervals (ITI). e Non-normalized port entries in each CS trial decreased across test, but did not differ between contexts. Data are presented as means \pm SEM. ${ }^{*} p<0.05$ for paired $t$-tests. Statistical tests were paired $t$-tests (b-d) and repeated measures ANOVA (e). Data from individual rats are depicted as gray dots (b-d)

(Fig. 4a). Normalized CS port entries were higher in the sugar context than in the neutral context (Context, $F_{1,14}=29.383, p<$ 0.001). MTEP microinfused into the BLA had no impact on CS port entries (Treatment, $F_{1,14}=1.193, p=0.293$ ) in either context (Context $\times$ Treatment, $F_{1,14}=0.25, p=0.625$ ).

Similarly, CS port entries were initiated more rapidly in the sugar context (Fig. $4 b$; Context, $F_{1,14}=33.277, p<0.001$ ). However, there was no effect of MTEP on this measure (Treatment, $F_{1,14}=4.045$, $p=0.064)$ in either context (Context $\times$ Treatment, $F_{1,14}=0.004$, $p=0.95)$.

There was also no effect of intra-BLA MTEP on CS port entries on a per trial basis (Fig. S4b).

There was also no effect of intra-BLA MTEP on port entries made during the ITI (Fig. 4C). Kolmogorov-Smirnov tests detected significant violations of the assumption of normality in the sugar context following MTEP $\left(D_{15}=0.294, p=0.001\right)$ and in the neutral 


\section{Systemic MTEP but not MK-801 reduced CS port entries}
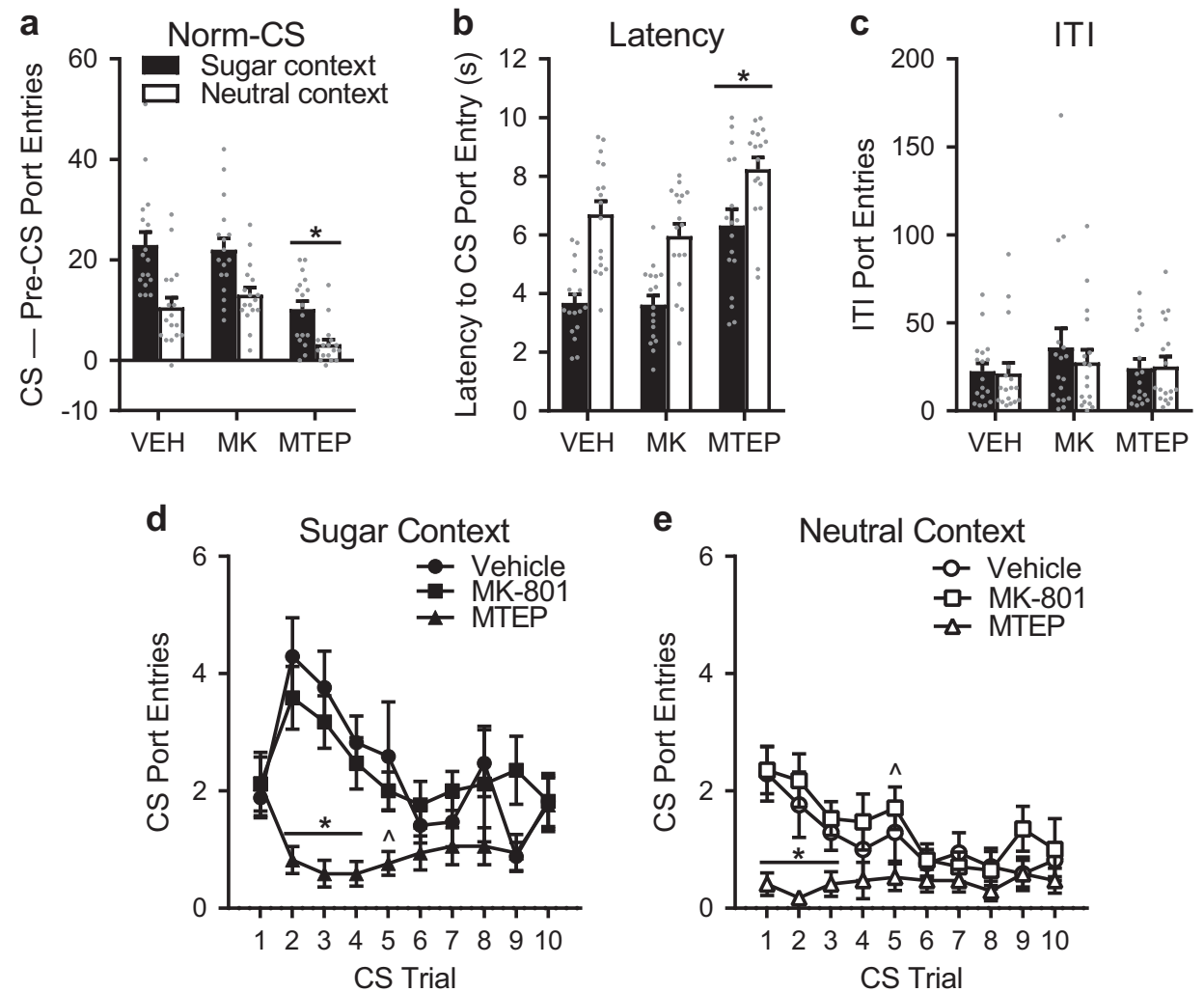

Fig. 2 Systemic MTEP but not MK-801 reduced CS port entries. a We tested the expression of CS port entries in well-trained rats $(n=17)$ following systemic injections of vehicle, $0.1 \mathrm{mg} / \mathrm{kg} \mathrm{MK-801,} \mathrm{or} 5 \mathrm{mg} / \mathrm{kg}$ MTEP in a counterbalanced, within-subjects design. Normalized CS port entries (CS-Pre-CS port entries) were elevated in the sugar context relative to the neutral context, and reduced following MTEP, but not MK-801, in both contexts. b The first CS port entry took longer to occur in both contexts following MTEP, but not MK-801. c MTEP had no effect on port entries during the ITI. $\mathbf{d}$ In the sugar context, non-normalized CS port entries were significantly reduced by MTEP in the first half of the session, beginning in the second CS trial. e In the neutral context, MTEP reduced CS port entries in the first half of the session, but beginning on the first trial. Data are presented as means \pm SEM. ${ }^{*} p<0.05$ Bonferroni post-hoc comparisons for MTEP compared to vehicle and MK-801. $\wedge p<0.05$ Bonferroni post-hoc comparisons for MTEP compared to MK-801. Statistical tests were repeated measures ANOVAs. Data from individual rats are depicted as gray dots (a-c)

context following vehicle $\left(D_{15}=0.246, p=0.015\right)$. We therefore performed a non-parametric Friedman's two-way ANOVA, which was not significant $\left(Q_{3}=5.834, p=0.12\right)$.

Despite these null results, an exploratory analysis of the data suggested that MTEP in the BLA might suppress CS port entries in a topographically dependent manner. In the anteroposterior (AP) axis, the bulk of the rat BLA encompasses -1.56 to $-3.36 \mathrm{~mm}$ from bregma, with some small subnuclei extending to nearly $-5 \mathrm{~mm}$ $[35,36]$. Several studies have shown differential behavioral and neurophysiological effects depending on AP BLA topography $[22,37-39]$. Based on these reports, we examined the possibility that the effect of MTEP in the BLA might vary as a function of topography. For this we plotted the change score for normalized CS port entries $\left(\Delta\right.$ norm-CS $=$ norm- $-\mathrm{CS}_{\text {MTEP }}$ minus norm- $\left.-\mathrm{CS}_{\text {Vehicle }}\right)$ as a function of the AP coordinates of the microinjection placement (Fig. 4d). A negative change score in this analysis reflects a reduction in CS port entries following MTEP, relative to vehicle. Interestingly, we found significant correlations between the AP coordinates of the microinjection site, and $\Delta$ norm-CS in the sugar context $\left(r_{13}=-0.629\right.$, $p=0.012)$ and neutral context $\left(r_{13}=-0.729, p=0.002\right)$. These results suggest that mGluR5 located more anteriorly in the BLA might preferentially contribute to CS port entries in both contexts.

Histological verification of microinjection sites (Fig. 4h; see also Fig. S5b) resulted in the exclusion of four rats with inaccurate cannula placements and one rat that died in surgery (final $n=15$ ).
MTEP in the anterior basolateral amygdala enhanced the contextbased discrimination of CS port entries

In separate rats $(n=24)$, we tested the hypothesis that mGluR5 in the anterior BLA might be preferentially involved in CS port entries. As in all prior experiments, normalized CS port entries at test were elevated in the sugar context relative to the neutral context (Fig. 4e; Context, $F_{1,16}=29.037, p<0.001$ ). MTEP microinjections targeting the anterior aspect of the BLA had no overall impact on CS port entries (Treatment, $F_{1,16}=0.164$ ). However, a significant Context $\times$ Treatment interaction $\left(F_{1,16}=8.771, p=\right.$ 0.009) showed that there was a larger difference between CS port entries in the sugar and neutral contexts following MTEP, relative to vehicle. Although MTEP enhanced discrimination between contexts, Bonferroni-corrected post-hoc tests found no significant differences between vehicle and MTEP in either the sugar $(p=0.074)$ or neutral $(p=0.234)$ contexts

Rats were faster to respond to the CS (Fig. 4f) in the sugar context, relative to the neutral context (Context, $F_{1,16}=32.946$, $p<0.001$ ). Although MTEP did not impact latency to make a CS port entry overall (Treatment, $F_{1,16}=1.06, p=0.318$ ), there was a significant Context $\times$ Treatment interaction $\left(F_{1,16}=4.58, \quad p=\right.$ 0.048 ), indicating a larger difference in latency scores between sugar and neutral contexts following MTEP, compared to vehicle. Although MTEP enhanced discrimination between contexts, Bonferroni-corrected post-hoc tests found no significant 
MTEP in the nucleus accumbens core had no effect on CS port entries
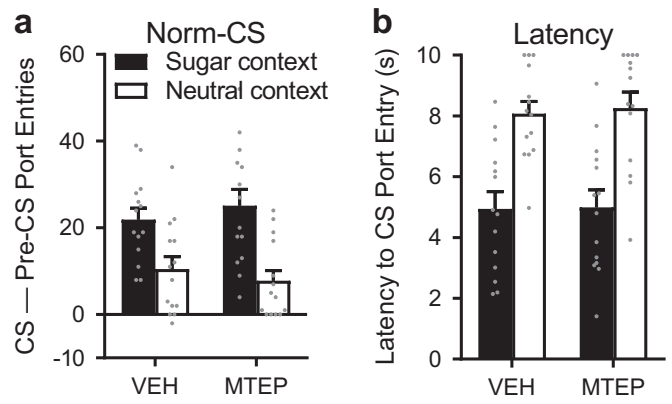

C
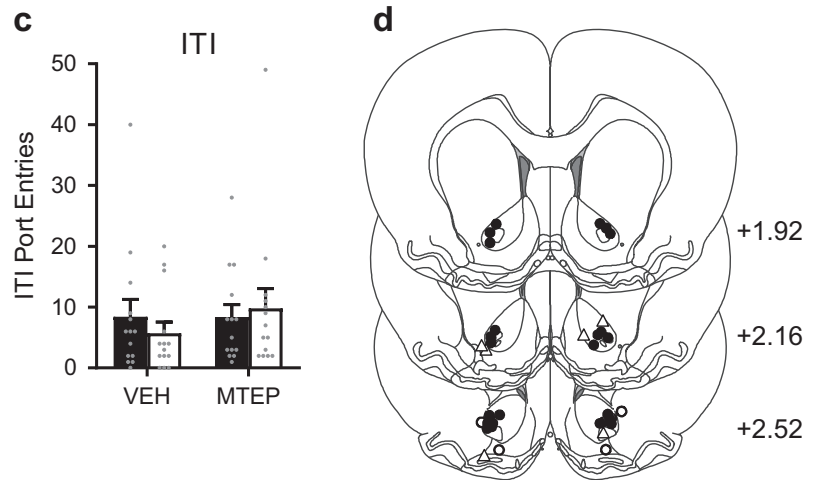

Fig. 3 MTEP microinjections targeting the nucleus accumbens (Acb) core had no effect on CS port entries. a Normalized CS port entries (CS-Pre-CS port entries) at test were elevated in the sugar context compared to the neutral context; however, there was no effect of $3 \mu \mathrm{g} / \mathrm{side}$ MTEP in the Acb core on CS port entries in either context. b The latency to the first CS port entry was unaffected by MTEP. c MTEP had no effect on port entries during the ITI. d Histological verification of microinjection sites. Two rats that lost head mounts, and 5 rats had misplaced cannulae (open circles, $O$; open triangles for unilateral placement, $\Delta$ ). Final $n=14$ (black circles, 0 ). Data are presented as means \pm SEM. Anteroposterior coordinates are given in $\mathrm{mm}$ from bregma. Statistical tests were repeated measures ANOVAs. Data from individual rats are depicted as gray dots (a-c)

differences between vehicle and MTEP in either the sugar ( $p=$ $0.094)$ or neutral $(p=0.335)$ contexts.

CS port entries on a per trial basis were no different following vehicle or MTEP in either context (Fig. S4c).

There was no effect of Context $\left(F_{1,16}=0.99, p=0.335\right)$ on ITI port entries (Fig. 4g), and no effect of MTEP microinjection in the anterior BLA on ITI port entries (Treatment, $F_{1,16}=3.41, p=0.083$ ) in either context (Context $\times$ Treatment, $F_{1,16}=0.184, p=0.673$ ).

The placements of microinjector tips for this study are shown in Fig. $4 \mathrm{i}$ (see also Fig. S5c). One rat died in surgery and six rats were excluded following histological verification (final $n=17$ ).

Thus, inhibiting mGluR5 in the anterior BLA appeared to enhance the context-based discrimination of CS port entries, resulting in a modest increase and more rapid onset of CS port entries in the sugar context, and a modest decrease and slower onset of CS port entries in the neutral context.

\section{DISCUSSION}

The present study produced several notable findings. We established that port entries elicited by a CS that predicted fructose-glucose solution ("sugar") were significantly elevated in a context associated with sugar, relative to a neutral context. Systemic administration of the NMDA glutamate receptor antagonist, MK-801, had no impact on behavior. However, systemic administration of the mGluR5 inhibitor, MTEP, selectively reduced CS port entries in the sugar and neutral contexts. The neural locus of this MTEP effect was not the Acb core; however, mGluR5 in the BLA was involved in the expression of CS port entries in a topographically dependent manner. Specifically, MTEP microinjections in the anterior BLA enhanced the contextbased discrimination of CS port entries. These results show that mGluR5 is involved in the expression of appetitive Pavlovian conditioned responding, and identify a topographical gradient within the BLA that defines a context-dependent role for mGluR5 in this behavior.

In well-trained rats, systemic injection of MTEP, but not MK-801, selectively reduced the number of CS port entries and increased the latency to respond to the CS in both sugar-associated and neutral contexts. The lack of effect of MTEP on ITI port entries in all our experiments suggests that inhibiting mGluR5, either systemically on within the Acb core or BLA, did not cause a non-specific decrease in locomotion. We also found that systemic MTEP $(5 \mathrm{mg} /$ $\mathrm{kg}$ ) had no impact on locomotor activity in an open field test or on the consumption of a fructose-glucose solution. Taken together, these results highlight a novel role for mGluR5 in the expression of conditioned responding elicited by appetitive Pavlovian cues, which complements the necessity of this receptor for the expression of operant behavior that is reinforced by drugpredictive cues [7-10].

We also observed an interesting difference in the within-session pattern of CS port entries at test. In the neutral context, systemic injection of MTEP produced an immediate reduction in CS port entries, suggesting that under these conditions, mGluR5 might be required for motivation to respond to a discrete $C S$, or for retrieving memories of the motivational value of an appetitive Pavlovian CS [18]. In the sugar context, there was no difference between MTEP and vehicle in the first CS trial, but a reduction following MTEP emerged thereafter. The latter results are consistent with the interpretation that inhibiting mGluR5 in the sugar context accelerated within-session extinction of CS port entries. mGluR5 has been implicated in extinction [12, 13]; however, results from operant studies suggest that mGluR5 receptor activation, rather than mGluR5 inhibition, facilitates extinction $[40,41]$. There may therefore be a difference in the role of mGluR5 in the extinction of appetitive Pavlovian and operant learning, an intriguing hypothesis that requires further research.

In the literature on operant drug reinforcement, sucrose selfadministration is often used as a control for reinforcer specificity. In several of these studies, neither systemic administration of MTEP nor intracerebral microinjection of MTEP into various brain regions had an effect on relapse to sucrose-seeking [7, 13, 42]. In contrast, we observed a significant effect of systemic and intraBLA MTEP on conditioned responding elicited by a cue that predicted a non-drug, fructose-glucose solution. Again, this intriguing difference could be related to the contribution of mGluR5 in the expression of behavior acquired through Pavlovian or operant learning strategies.

Based on our results, mGluR5 within the Acb core did not contribute to the expression of appetitive Pavlovian conditioning. In addition to no change in CS port entries relative to vehicle, there was no significant association between the effect of MTEP on CS port entries and the AP placement of microinjections (Fig. S6). These results were unexpected, because previous studies have shown that intra-Acb core microinjections of MTEP reduced operant drug-seeking behavior in relapse models [7, 13]. Moreover, cocaine-primed reinstatement upregulated Acb core mGluR5 [43], and mGluR5 in the Acb core is necessary for the interoceptive effects of alcohol to be expressed [44]. One explanation for why our data differ from the operant relapse studies is that in our task the CS was not systematically extinguished prior to test, whereas 

in CS port entries
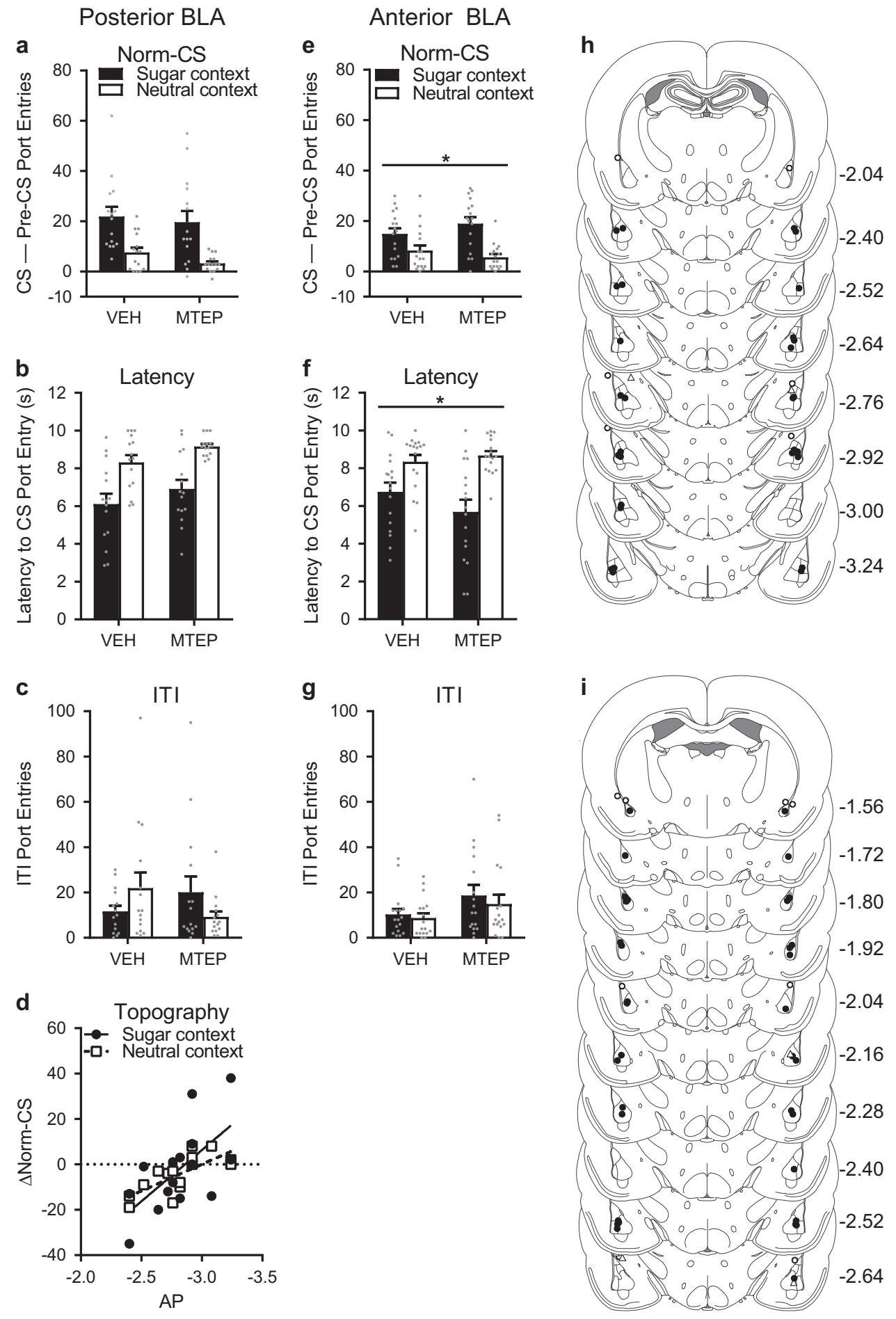

in operant relapse models instrumental responding is rigorously extinguished across consecutive sessions before reinstatement tests. Extinction learning induced by this protocol might engage mGluR5 in the Acb core and influence the role of this receptor in subsequent reinstatement tests. This hypothesis is supported by the finding that MTEP in the Acb core did not impact on-going operant alcohol self-administration that had not previously been extinguished [45]. Notably, in the present procedure CS port entries were incompletely extinguished in each test, and one or two Pavlovian conditioning sessions were conducted between tests.

In separate experiments, MTEP microinjections that encompassed more posterior BLA coordinates had no overall effect on CS port entries. A follow-up experiment with placements that covered more anterior aspects of the BLA and overlapped only with the most anterior coordinates from our first BLA experiment found that MTEP microinjections had a differential impact on CS port entries in the sugar and neutral contexts. Specifically, 
Fig. 4 Anterior targeting of the basolateral complex of the amygdala (BLA) enhanced context-based differences in CS port entries. a In rats with cannulae targeting the posterior BLA, CS port entries were elevated at test in the sugar context compared to the neutral context. However, there was no effect of MTEP on normalized CS port entries (CS-Pre-CS port entries), $\mathbf{b}$ latency to the first CS port entry, or c ITI port entries. d Exploratory analysis showed that more anterior BLA cannula placements were associated with greater reductions in normalized CS port entries following $3 \mu \mathrm{g} / \mathrm{side}$ MTEP ( $\Delta$ norm-CS $=$ norm- $-\mathrm{CS}_{\mathrm{MTEP}}-$ norm- $\mathrm{CS}_{\text {Vehicle }}$ ). Therefore, a separate experiment targeting the anterior BLA was conducted. e In this separate experiment, normalized CS port entries at test were elevated in the sugar context compared to the neutral context and MTEP significantly increased the context-based differences in CS port entries, $\mathbf{f}$ as well as the latency to the first CS port entry. $\mathbf{g}$ There was no effect of MTEP on ITI port entries. $\mathbf{h}$ Histological verification of posterior BLA microinjection sites. One rat died in surgery and 4 rats had misplaced cannulae (open circles, $\bigcirc$; open triangles for unilateral placement, $\Delta$ ). Final $n=15$ (black circles, $\mathbf{O}$ ). i Histological verification of anterior BLA microinjection sites. One rat died in surgery and 6 rats had misplaced cannulae (open circles, $O$ ). Final $n=17$ (black circles, 0$)$. Data are presented as means \pm SEM. ${ }^{*} p<0.05$ for a Treatment $\times$ Context interaction. All statistical tests were repeated measures ANOVAs except the Pearson correlation in panel (d). Data from individual rats are depicted as gray dots (a-c, e-g)

inhibiting mGluR5 in more anterior aspects of the BLA enhanced the context-based discrimination of CS port entries, resulting in a modest increase and more rapid onset of CS port entries in the sugar context, and a modest decrease and slower onset of CS port entries in the neutral context. One caveat here is that following vehicle microinjections, CS port entries in the sugar context were lower for rats with anterior BLA placements relative to other experiments. However, this anomaly is countered by the withinsubject experimental design, which accommodates for differences in overall levels of behavior that may emerge between experiments. Indeed, rats in each experiment made a number of CS port entries in the sugar context following vehicle microinjection that was comparable with their performance in session 10 of Pavlovian conditioning (posterior BLA targeting, $M=20.9 \pm 4.15$ SEM; anterior BLA targeting, $M=15.3 \pm 2.15$ SEM).

The anatomic correlation found when targeting more posterior BLA coordinates predicted an MTEP effect with more anterior targeting, but did not predict the enhanced contextual discrimination. This outcome highlights the importance of confirming exploratory analyses. One explanation for the present results could be related to the topographical distribution of mGluR5 in the BLA: while this is consistently dense throughout the BLA [46] the smaller size of the anterior BLA may mean that fewer neurons overall express $\mathrm{mGluR5}$ in the anterior BLA relative to the posterior BLA (Fig. S7). Another consideration is the relation between the present data and prior research suggesting that excitatory pyramidal neurons in the anterior and posterior BLA are important for aversive and appetitive behaviors, respectively [47]. While these findings do not appear consistent with the present data, additional studies are needed to evaluate the effect of MTEP on these specific neuronal subpopulations on context-dependent responding to appetitive Pavlovian cues.

The present results suggest that mGluR5 in anterior BLA normally suppresses CS port entries in a sugar-associated context, but is necessary for this behavior in a neutral context. These differential effects could be related to the modulation of glutamate release in the anterior BLA by context, which could signal expectancy of sugar, potentially through hippocampal inputs to the BLA. The observed results in the anterior BLA are consistent with reports that inactivation of the anterior but not posterior BLA reduced cue-induced reinstatement of cocaine seeking [39], and that prelimbic projections to the anterior but not posterior BLA were recruited during the acquisition of appetitive Pavlovian learning [38]. Circuits involving the anterior BLA were also required for cue-induced reinstatement of cocaine seeking [48] and extinction learning [49]. The BLA has topographically defined projections, with the anterior BLA projecting more to the Acb core [50] and posterior BLA projecting to the shell [51]. The density of projections from the BLA to the ventral hippocampus, central amygdala, and Acb also varies along the AP axis [52]. Further research is necessary to evaluate the contribution of distinct topographically defined BLA circuits to the contextdependent expression of appetitive Pavlovian responding.
In conclusion, the present results reveal an influential role for environmental context in responding to an appetitive Pavlovian cue. The finding that CS port entries were elevated in a sugar context relative to a neutral context was replicated in four separate experiments, highlighting the importance of considering context in experimental design. mGluR5 emerged as critical for the expression of CS port entries, as this behavior was reduced by systemic MTEP administration in both a sugar context and a neutral context. In contrast, a behaviorally effective dose of the NMDA receptor antagonist, MK-801, had no impact on behavior. mGluR5 in the anterior BLA had differing, context-based functions in CS port entries, whereas mGluR5 in the Acb core or posterior BLA did not contribute to this behaviour. These novel data add to our overall understanding of glutamatergic processes in appetitive Pavlovian conditioning, and contribute to a growing literature on the nuances of amygdala topography in emotional behaviour [22, $37-39,47,52,53]$.

\section{FUNDING AND DISCLOSURES}

This research was supported by grants from the Canadian Institutes of Health Research (CIHR; MOP-137030 and the Natural Sciences and Engineering Research Council (NSERC; RGPIN-2017-04802). N.C. was supported by a Fonds de la recherche du Québec-Santé Chercheur-Boursier award and is a member of the Center for Studies in Behavioral Neurobiology/ FRQS Groupe de recherche en neurobiologie comportementale (CSBN/GRNC). S.Y.K. was supported by a Concordia Horizon Postdoctoral Fellowship. M.R.L. was supported by a graduate fellowship from the Faculty of Arts and Science at Concordia University.

\section{ACKNOWLEDGEMENTS}

The authors gratefully acknowledge Belinda P. P. Lay for experiment suggestions, Franz Villaruel and Milan Valyear for assistance with blind histology, and Uri Shalev for access to locomotor testing equipment.

\section{ADDITIONAL INFORMATION}

Supplementary Information accompanies this paper at (https://doi.org/10.1038/ s41386-019-0335-6).

Competing interests: The authors declare no competing interests.

Publisher's note: Springer Nature remains neutral with regard to jurisdictional claims in published maps and institutional affiliations.

\section{REFERENCES}

1. Kalivas PW, Volkow ND. The neural basis of addiction: a pathology of motivation and choice. Am J Psychiatry. 2005;162:1403-13. https://doi.org/10.1176/appi. ajp.162.8.1403 
2. Brown RM, Kupchik YM, Kalivas PW. The story of glutamate in drug addiction and of $\mathrm{n}$-acetylcysteine as a potential pharmacotherapy. JAMA Psychiatry. 2013;70:895-7. https://doi.org/10.1001/jamapsychiatry.2013.2207

3. Brown RM, Kupchik YM, Spencer S, Garcia-Keller C, Spanswick DC, Lawrence AJ. et al. Addiction-like synaptic impairments in diet-induced obesity. Biol Psychiatry. 2017:81:797-806.

4. Sengmany K, Gregory KJ. Metabotropic glutamate receptor subtype 5: molecular pharmacology, allosteric modulation and stimulus bias. $\mathrm{Br} J$ Pharmacol. 2016;173:3001-17. https://doi.org/10.1111/bph.13281

5. Haass-Koffler CL, Goodyear K, Long VM, Tran HH, Loche A, Cacciaglia R, et al. A Phase I randomized clinical trial testing the safety, tolerability and preliminary pharmacokinetics of the mGluR5 negative allosteric modulator GET 73 following single and repeated doses in healthy volunteers. Eur J Pharm Sci. 2017;109:78-85. https://doi.org/10.1016/j.ejps.2017.07.031

6. Caprioli D, Justinova Z, Venniro M, Shaham Y. Effect of novel allosteric modulators of metabotropic glutamate receptors on drug self-administration and relapse: $A$ review of preclinical studies and their clinical implications. Biol Psychiatry. 2018;84:180-92. https://doi.org/10.1016/j.biopsych.2017.08.018

7. Sinclair CM, Cleva RM, Hood LE, Olive MF, Gass JT. mGluR5 receptors in the basolateral amygdala and nucleus accumbens regulate cue-induced reinstatement of ethanol-seeking behavior. Pharmacol Biochem Behav. 2012;101:329-35. https://doi.org/10.1016/j.pbb.2012.01.014

8. Bäckström P, Bachteler D, Koch S, Hyytiä P, Spanagel R. mGluR5 antagonist MPEP reduces ethanol-seeking and relapse behavior. Neuropsychopharmacology. 2004;29:921 https://doi.org/10.1038/sj.npp.1300381

9. Cowen MS, Djouma E, Lawrence AJ. The metabotropic glutamate 5 receptor antagonist 3-[(2-methyl-1,3-thiazol-4-yl)ethynyl]-pyridine reduces ethanol selfadministration in multiple strains of alcohol-preferring rats and regulates olfactory glutamatergic systems. J Pharmacol Exp Ther. 2005;315:590-600. https://doi. org/10.1124/jpet.105.090449

10. Tessari M, Pilla M, Andreoli M, Hutcheson DM, Heidbreder CA. Antagonism at metabotropic glutamate 5 receptors inhibits nicotine- and cocaine-taking behaviours and prevents nicotine-triggered relapse to nicotine-seeking. Eur J Pharmacol. 2004;499:121-33. https://doi.org/10.1016/j.ejphar.2004.07.056

11. Chiamulera C, Epping-Jordan MP, Zocchi A, Marcon C, Cottiny C, Tacconi S, et al. Reinforcing and locomotor stimulant effects of cocaine are absent in mGluR5 null mutant mice. Nat Neurosci. 2001;4:873. https://doi.org/10.1038/nn0901-873

12. Chesworth R, Brown RM, Kim JH, Lawrence AJ. The metabotropic glutamate 5 receptor modulates extinction and reinstatement of methamphetamine-seeking in mice. PLoS One. 2013;8:e68371. https://doi.org/10.1371/journal.pone.0068371

13. Knackstedt LA, Trantham-Davidson $\mathrm{HL}$, Schwendt $M$. The role of ventral and dorsal striatum mGluR5 in relapse to cocaine-seeking and extinction learning. Addict Biol. 2014;19:87-101. https://doi.org/10.1111/adb.12061

14. Field M, Cox WM. Attentional bias in addictive behaviors: a review of its development, causes, and consequences. Drug Alcohol Depend. 2008;97:1-20. https:// doi.org/10.1016/j.drugalcdep.2008.03.030

15. Handford CE, Tan S, Lawrence AJ, Kim JH. The effect of the mGlu5 negative allosteric modulator MTEP and NMDA receptor partial agonist D-cycloserine on Pavlovian conditioned fear. Int J Neuropsychopharmacol. 2014;17:1521-32. https://doi.org/10.1017/S1461145714000303

16. Gravius A, Barberi C, Schäfer D, Schmidt WJ, Danysz W. The role of group I metabotropic glutamate receptors in acquisition and expression of contextual and auditory fear conditioning in rats-a comparison. Neuropharmacology. 2006;51:1146-55. https://doi.org/10.1016/j.neuropharm.2006.07.008

17. Simonyi A, Serfozo P, Parker KE, Ramsey AK, Schachtman TR. Metabotropic glutamate receptor 5 in conditioned taste aversion learning. Neurobiol Learn Mem. 2009:92:460-3. https://doi.org/10.1016/j.nlm.2009.05.002

18. O'Connor EC, Crombag HS, Mead AN, Stephens DN. The mGluR5 antagonist MTEP dissociates the acquisition of predictive and incentive motivational properties of reward-paired stimuli in mice. Neuropsychopharmacology. 2010;35:1807 https:// doi.org/10.1038/npp.2010.48

19. Meyers AM, Mourra D, Beeler JA. High fructose corn syrup induces metabolic dysregulation and altered dopamine signaling in the absence of obesity. PLoS ONE. 2017;12:e0190206 https://doi.org/10.1371/journal.pone.0190206

20. Hoebel BG, Avena NM, Bocarsly ME, Rada P. Natural addiction: a behavioral and circuit model based on sugar addiction in rats. J Addict Med. 2009;3:33-41. https://doi.org/10.1097/ADM.0b013e31819aa621

21. Sciascia JM, Reese RM, Janak PH, Chaudhri N. Alcohol-seeking triggered by discrete pavlovian cues is invigorated by alcohol contexts and mediated by glutamate signaling in the basolateral amygdala. Neuropsychopharmacology. 2015;40:2801-12. https://doi.org/10.1038/npp.2015.130

22. Millan EZ, Reese RM, Grossman CD, Chaudhri N, Janak PH. Nucleus accumbens and posterior amygdala mediate cue-triggered alcohol seeking and suppress behavior during the omission of alcohol-predictive cues. Neuropsychopharmacology. 2015;40:2555-65. https://doi.org/10.1038/npp.2015.102
23. Valyear MD, Glovaci I, Zaari A, Lahlou S, Trujillo-Pisanty I, Chapman CA et al. Divergent mesolimbic dopamine circuits support alcohol-seeking triggered by discrete cues and contexts. bioRxiv. 2018:475343. https://doi.org/10.1101/475343

24. Mihov Y, Hasler G. Negative allosteric modulators of metabotropic glutamate receptors subtype 5 in addiction: a therapeutic window. Int J Neuropsychopharmacol. 2016;19:pyw002-pyw. https://doi.org/10.1093/ijnp/pyw002

25. Parkes SL, Westbrook RF. The basolateral amygdala is critical for the acquisition and extinction of associations between a neutral stimulus and a learned danger signal but not between two neutral stimuli. J Neurosci. 2010;30:12608-18. https:// doi.org/10.1523/jneurosci.2949-10.2010

26. Homayoun $\mathrm{H}$, Moghaddam B. Bursting of prefrontal cortex neurons in awake rats is regulated by metabotropic glutamate 5 (mGlu5) receptors: rate-dependent influence and interaction with NMDA receptors. Cereb Cortex. 2006;16:93-105. https://doi.org/10.1093/cercor/bhi087

27. Homayoun H, Stefani MR, Adams BW, Tamagan GD, Moghaddam B. Functional interaction between NMDA and mGlu5 receptors: Effects on working memory, instrumental learning, motor behaviors, and dopamine release. Neuropsychopharmacology. 2004;29:1259. https://doi.org/10.1038/sj.npp.1300417

28. Fowler SW, Ramsey AK, Walker JM, Serfozo P, Olive MF, Schachtman TR, et al. Functional interaction of mGlu5 and NMDA receptors in aversive learning in rats. Neurobiol Learn Mem. 2011;95:73-9. https://doi.org/10.1016/j.nlm.2010.11.009

29. Khoo SY-S, Uhrig A, Chaudhri N. Context does not invigorate responding to a neutral stimulus. Figshare. 2019. https://doi.org/10.6084/m9.figshare.7483478

30. Chaudhri N, Woods CA, Sahuque LL, Gill TM, Janak PH. Unilateral inactivation of the basolateral amygdala attenuates context-induced renewal of pavlovianconditioned alcohol-seeking. Eur J Neurosci. 2013;38:2751-61. https://doi.org/ 10.1111/ejn.12278

31. Panayi MC, Killcross S. Functional heterogeneity within the rodent lateral orbitofrontal cortex dissociates outcome devaluation and reversal learning deficits. eLife . 2018;7:e37357. https://doi.org/10.7554/eLife.37357

32. Khoo SY-S, LeCocq MR, Deyab GE, Chaudhri N. Context and topography determine the role of basolateral amygdala metabotropic glutamate receptor 5 in appetitive Pavlovian responding. Figshare. 2019. https://doi.org/10.6084/m9. figshare.7045493

33. Gass JT, Osborne MPH, Watson NL, Brown JL, Olive MF. mGluR5 antagonism attenuates methamphetamine reinforcement and prevents reinstatement of methamphetamine-seeking behavior in rats. Neuropsychopharmacology. 2009;34:820. https://doi.org/10.1038/npp.2008.140

34. Knackstedt LA, Schwendt M. mGlu5 receptors and relapse to cocaine-seeking: the role of receptor trafficking in postrelapse extinction learning deficits. Neural Plast. 2016;2016:9312508. https://doi.org/10.1155/2016/9312508

35. Paxinos G, Watson C. The rat brain in stereotaxic coordinates. 6th ed. London: Academic Press; 2007.

36. Swanson LW. Brain maps 4.0-Structure of the rat brain: an open access atlas with global nervous system nomenclature ontology and flatmaps. J Comp Neurol. 2018;526:935-43. https://doi.org/10.1002/cne.24381

37. McLaughlin RJ, Floresco SB. The role of different subregions of the basolateral amygdala in cue-induced reinstatement and extinction of food-seeking behavior. Neuroscience . 2007;146:1484-94. https://doi.org/10.1016/j.neuroscience.2007.03.025

38. Keefer SE, Petrovich GD. Distinct recruitment of basolateral amygdala-medial prefrontal cortex pathways across Pavlovian appetitive conditioning. Neurobiol Learn Mem. 2017;141:27-32. https://doi.org/10.1016/j.nlm.2017.03.006

39. Kantak KM, Black Y, Valencia E, Green-Jordan K, Eichenbaum HB. Dissociable effects of lidocaine inactivation of the rostral and caudal basolateral amygdala on the maintenance and reinstatement of cocaine-seeking behavior in rats. J Neurosci. 2002;22:1126-36. https://doi.org/10.1523/jneurosci.22-03-01126.2002

40. Gass JT, Olive MF. Positive allosteric modulation of mGluR5 receptors facilitates extinction of a cocaine contextual memory. Biol Psychiatry. 2009;65:717-20. https://doi.org/10.1016/j.biopsych.2008.11.001

41. Perry CJ, Reed F, Zbukvic IC, Kim JH, Lawrence AJ. The metabotropic glutamate 5 receptor is necessary for extinction of cocaine-associated cues. $\mathrm{Br} J$ Pharmacol. 2016;173:1085-94. https://doi.org/10.1111/bph.13437

42. Kumaresan V, Yuan M, Yee J, Famous KR, Anderson SM, Schmidt HD, et al. Metabotropic glutamate receptor 5 (mGluR5) antagonists attenuate cocaine priming- and cue-induced reinstatement of cocaine seeking. Behav Brain Res. 2009;202:238-44. https://doi.org/10.1016/j.bbr.2009.03.039

43. Georgiou $\mathrm{P}$, Zanos $\mathrm{P}$, Ehteramyan M, Hourani S, Kitchen I, Maldonado R, et al. Differential regulation of mGlu5R and MOPr by priming- and cue-induced reinstatement of cocaine-seeking behaviour in mice. Addict Biol. 2015;20:902-12. https://doi.org/10.1111/adb.12208

44. Besheer J, Grondin JJM, Salling MC, Spanos M, Stevenson RA, Hodge CW. Interoceptive effects of alcohol require mGlu5 receptor activity in the nucleus accumbens. J Neurosci. 2009;29:9582-91. https://doi.org/10.1523/jneurosci.236609.2009 
Context and topography determine the role of basolateral amygdala... S. Y.-S. Khoo et al.

45. Gass JT, Olive MF. Role of protein kinase $\mathrm{C}$ epsilon $(\mathrm{PKC} \varepsilon$ ) in the reduction of ethanol reinforcement due to mGluR5 antagonism in the nucleus accumbens shell. Psychopharmacology. 2009;204:587-97. https://doi.org/10.1007/s00213-009-1490-y

46. Lein ES, Hawrylycz MJ, Ao N, Ayres M, Bensinger A, Bernard A, et al. Genome-wide atlas of gene expression in the adult mouse brain. Nature. 2007;445:168-76. https://doi.org/10.1038/nature05453

47. Kim J, Pignatelli M, Xu S, Itohara S, Tonegawa S. Antagonistic negative and positive neurons of the basolateral amygdala. Nat Neurosci. 2016;19:1636. https://doi.org/10.1038/nn.4414

48. Mashhoon Y, Wells AM, Kantak KM. Interaction of the rostral basolateral amygdala and prelimbic prefrontal cortex in regulating reinstatement of cocaineseeking behavior. Pharmacol Biochem Behav. 2010;96:347-53. https://doi.org/ 10.1016/j.pbb.2010.06.005

49. Szalay JJ, Morin ND, Kantak KM. Involvement of the dorsal subiculum and rostral basolateral amygdala in cocaine cue extinction learning in rats. Eur J Neurosci. 2011;33:1299-307. https://doi.org/10.1111/j.1460-9568.2010.07581.x
50. Wright $\mathrm{Cl}$, Groenewegen HJ. Patterns of overlap and segregation between insular cortical, intermediodorsal thalamic and basal amygdaloid afferents in the nucleus accumbens of the rat. Neuroscience. 1996;73:359-73. https://doi.org/10.1016/ 0306-4522(95)00592-7

51. Wright $\mathrm{Cl}$, Groenewegen $\mathrm{HJ}$. Patterns of convergence and segregation in the medial nucleus accumbens of the rat: relationships of prefrontal cortical, midline thalamic, and basal amygdaloid afferents. J Comp Neurol. 1995;361:383-403. https://doi.org/10.1002/cne.903610304

52. Beyeler A, Chang C-J, Silvestre $M$, Lévêque $C$, Namburi $P$, Wildes $C P$, et al. Organization of valence-encoding and projection-defined neurons in the basolateral amygdala. Cell Rep. 2018;22:905-18. https://doi.org/10.1016/j. celrep.2017.12.097

53. Janak PH, Tye KM. From circuits to behaviour in the amygdala. Nature 2015;517:284-92. https://doi.org/10.1038/nature14188 